\title{
A AFETIVIDADE COMO FERRAMENTA PEDAGÓGICA NO PROCESSO DE ENSINO-APRENDIZAGEM DE JOVENS E ADULTOS
}

\author{
SILVA, Silvia Leticia Losada ${ }^{1}$ \\ SILVA, Tatiana Luna Gomes ${ }^{2}$
}

\section{RESUMO}

O objetivo deste trabalho é discutir de que forma a afetividade, como ferramenta de trabalho docente, em especial com alunos da EJA (Educação de jovens e adultos), pode tornar os estudantes mais receptivos ao aprendizado. Abordamos a afetividade na perspectiva de autores como Henri Wallon, Jean Piaget e Lev S. Vygotsky, buscando compreender e dialogar suas concepções sobre o tema. Descrevemos aqui, dados oriundos da pesquisa realizada na EJA, onde através dos relatos e observações notamos que, estes alunos são adultos que carregaram consigo problemas emocionais e marcas de um período escolar onde seus valores não se ajustavam aos valores da escola, o que dificulta o aprendizado. Ao utilizar a afetividade, o professor faz com que os alunos sintam-se aceitos, receptivos ao aprendizado e ao convívio social. Ao confrontar os referenciais teóricos com os dados obtidos, percebe-se que apesar da experiência positiva observada, ainda existem paradigmas históricos de um ensino tecnicista, desta forma, não só a EJA é prejudicada em seus objetivos, mas a própria evasão escolar tem como fator colaborativo a relação distante entre aluno e professor.

Palavras-Chave: Afetividade - Aprendizagem - Educação de jovens e adultos.

\section{ABSTRACT}

The aim of this paper is to discuss how the affectivity, as teaching tools, especially with students of the EJA (Young and adults education), can turn students more receptive to learning. We approach affectivity according to authors as Henri Wallon, Jean Piaget and Lev S. Vygotsky, seeking to understand and discuss their conceptions about the theme. We described herein, data from the experience in EJA, where through the reports and observations we note that these students are adults who had carried emotional problems and marks of a school period where their values did not conform to values of the school, making it difficult to learning. Using the affectivity, the teacher makes the students feel accepted, receptive to learning and social interaction. By confronting the theoretical frameworks with the obtained data, we can see that despite positive experience, there are historical paradigms in a tech-

\footnotetext{
${ }^{1}$ Graduada pelo CEDERJ da Universidade Federal do Rio de Janeiro.

2 Professora Adjunta de Biologia do Instituto de Aplicação Fernando Rodrigues da Silveira (CAp-UERJ). Email: luna.gomest@gmail.com
} 
e-Mosaicos - Revista Multidisciplinar de Ensino, Pesquisa, Extensão e Cultura do Instituto de Aplicação Fernando Rodrigues da Silveira (CAp-UERJ)

V. 5 - N. 10 - DEZEMBRO 2016 - ISSN: 2316-9303

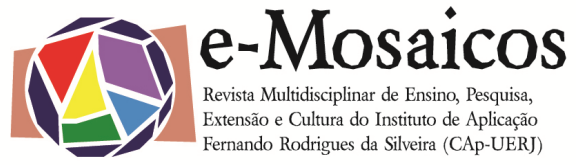

nical school, thus, not only the EJA is impaired in its objectives, but also the school dropout itself has as collaborative factor the distant relationship between student and teacher.

KEYWORDS: Affectivity - Learning - Young and adults education.

\section{INTRODUÇÃO}

\section{AfETIVIDADE NO PROCESSO ENSINO- APRENDIZAGEM}

Sentimentos, como a razão e a emoção são indissociáveis, e o ser humano pensa e sente de forma simultânea, a emoção está sempre presente em suas relações; desta forma a afetividade e a cognição se tornam também indissociáveis, tomando parte de um processo que não pode ser analisado separadamente (LEITE, 2012).

A afetividade é a parte psíquica responsável pelo significado sentimental de tudo que vivemos. Se algo que vivenciamos está sendo agradável, prazeroso, sofrível, angustiante, causa medo ou pânico, ou nos dá satisfação, são atribuídos pela nossa afetividade. Segundo Rossini (2001), a afetividade acompanha o ser humano desde o nascimento até a morte. Ela está em nós como uma fonte geradora de potência de energia. Assim, a afetividade é essencial em qualquer momento da vida do ser humano, pois ela se manifesta ao decorrer da vida em todos os momentos e em todas as relações sociais.

$\mathrm{O}$ afeto desempenha um papel importante, pois sem ele não haveria interesse, necessidade e motivação, e consequentemente os problemas não seriam questionados. De acordo com Piaget apud Seber:

"As construções intelectuais são permeadas passo a passo pelo aspecto afetivo e ele é muito importante. Tal aspecto diz respeito aos interesses, motivações, afetos, facilidades, esforço, ou seja, ao conjunto de sentimentos que acompanha cada ação realizada da criança.
A afetividade é o motor das condutas. Ninguém se esforçará para resolver um problema de matemática, por exemplo, se não se interessar em absoluto pela disciplina." (SEBER, 1997, p. 216).

Percebemos então que os aspectos afetivos e cognitivos se relacionam mutuamente; em cada situação eles estão presentes influenciando as ações do sujeito. A escola é um espaço onde se encontram diferentes valores, experiências, concepções, culturas, crenças e relações sociais que fazem do cotidiano escolar uma rica e complexa estrutura de conhecimentos e de sujeitos. Entretanto, esse ambiente heterogêneo geralmente entra em conflito com estruturas pedagógicas tradicionalistas. No cotidiano escolar as relações têm se mostrado cada dia mais difíceis e conflitantes. Segundo Wallon apud Galvão:

"No cotidiano escolar são comuns às situações de conflito envolvendo professor e alunos. Turbulência e agitação motora, dispersão, crises emocionais desentendimentos entre alunos e destes com o professor são alguns exemplos de dinâmicas conflituais, que com frequência deixam a todos desamparados e sem saber o que fazer. Irritação, raiva, desespero e medo são manifestações que costumam acompanhar as crises, funcionando como termômetro do conflito." (GALVÃO, 1995, p. 104).

O professor em seu exercício da profissão precisa estar devidamente apto para lidar com conflitos, posto que a relação "eu - outro" via de regra é conflituosa, quando não há aceitação do outro como 
e-Mosaicos - Revista Multidisciplinar de Ensino, Pesquisa, Extensão e Cultura do Instituto de Aplicação Fernando Rodrigues da Silveira (CAp-UERJ)

legítimo outro na convivência (MATURANA, 2008). Para Freire:

"O desrespeito à educação, aos educandos, aos educadores e educadoras, corrói ou deteriora em nós, de um lado a sensibilidade ou a abertura do bem querer que da prática educativa, de outro, a alegria necessária ao fazer docente. É digna de nota a capacidade que tem a experiência pedagógica para despertar, estimular e desenvolver em nos o gosto de querer bem 0 gosto de alegria sem a qual a prática educativa perde ao sentido" (FREIRE, 1996, p. 142):

A afetividade envolve uma gama maior de manifestações que irá envolver as emoções (de origem biológica) e os sentimentos (de origem psicológica). De acordo com Walon, a afetividade é de vital importância para o desenvolvimento do ser humano, podendo afetar no desenvolvimento de forma positiva ou negativa, mas sempre gerando reações a seu estímulo. Deixando a Inteligência de ser 0 principal fator do desenvolvimento, Wallon defende que a vida psíquica é formada por três elementos- motora, afetiva e cognitiva - coexistindo e atuando de forma integrada. $O$ processo de aprendizagem depende tanto da capacidade biológica do indivíduo quanto do ambiente que o afeta de alguma forma. Ele nasce com algum talento, mas é o meio que permite que esse talento se desenvolva ou não (WALLON, apud GALVÃO, 1993).

O ambiente escolar possui papel de suma importância na formação dos alunos, é na escola que os seres humanos passam maior parte de suas vidas e é nela que ocorrem relações com professores e colegas que irão moldar o seu caráter e ajudar a definir que tipo de indivíduo se formará no futuro (CRUZ, 2012). A escola juntamente com a família são os núcleos mais importantes para formação do ser huma- no. São elas que nos ensinam a lidar com a mais variada gama de sentimentos como a frustração, alegrias e angústias. Da atuação conjunta depende a formação de um ser responsável e consciente de seus deveres (CRUZ, 2012).

O professor deve através da afetividade e empatia desenvolver estratégias de ensino para conquistar o aluno passando o conhecimento necessário para sua formação. Através das reações emotivas podemos encontrar indicadores que levam 0 professor a analisar a melhor estratégia a ser usada dentro da sala de aula com seus alunos (WALLON apud TASSONI, 2013). O professor deve ser amigo e proporcionar segurança dentro da sala de aula, incentivando seus alunos que muitas vezes não encontram nenhum incentivo em seu ambiente familiar. Dessa forma incentivará sua aprendizagem e o aluno terá o desejo de aprender e se sentirá capaz de enfrentar as dificuldades na conquista desse aprendizado. Por meio da afetividade e da comunicação facilitada, professor e aluno se tornam mais próximos e o aprendizado corre de forma mais efetiva (CRUZ, 2012).

Vygotsky também explica a afetividade de forma semelhante à Wallon; para ele, o homem nasce com suas características filogenéticas e através de sua inserção na cultura se formam funções superiores, que irão caracterizar o ser humano. Ele ainda denuncia a divisão histórica entre afeto e cognição como o maior problema psicológico da sua época. Para Vygotsky as emoções caminham do plano individual e biológico, para um plano superior e simbólico com sentidos e significados formados pela cultura (VYGOTSKY apud SARNOSKI, 2014).

Para Vygotsky, a formação se dá numa relação dialética entre o sujeito e a sociedade ao seu redor; dessa forma, para se estudar a aprendizagem é necessário compreender o ser humano como um ser que se forma em contato com a sociedade, existindo uma interação entre ambien- 
te e ser humano, onde um modifica o outro. Dessa forma, uma relação professoraluno construtiva é baseada em uma harmonia dos domínios que formam o indivíduo, construindo conhecimento por meio de ligações afetivas, pois como afirma Vygotsky "na ausência do outro, o homem não se constrói"; a educação é um ato social onde há elementos que exteriorizam nossos sentimentos tais como alegria, tristeza e satisfação. É o ato social que nos permite nos conhecermos e conhecermos o outro, ajudando no desenvolvimento e aprendizagem de todos que formam 0 ambiente escolar (VYGOTSKY apud SARNOSKI, 2014).

\section{Perfil dos alunos da eja}

A história da educação de jovens e adultos é relativamente recente em nosso país. A ideia de oferecer educação era vista como desnecessária e perigosa para as classes dominantes. $O$ gasto de dinheiro com a alfabetização de adultos já inseridos no mercado de trabalho era visto como desperdício, bastando um treinamento que atendesse as necessidades do trabalho braçal na agricultura e na indústria (CRUZ, 2012).

Em 1974, foi criado o Centro de Estudos Supletivos (CES), onde através de uma educação rápida e superficial os adultos tinham a chance de obter um ensino tecnicista e auto-instrucional. Somente em 1988, a Constituição passou a garantir o ensino fundamental gratuito e obrigatório para todos. E então, o Brasil iniciou o processo de mobilização para as ações da EJA (CRUZ, 2012).

A Lei de Diretrizes e Bases (LDB) garante a todos a igualdade de acesso e permanência na escola e ensino de qualidade (Lei no 9.394, de 20 de dezembro de 1996). A LDB 9394/96, no seu artigo quinto, parágrafo primeiro, define, dentre outras, as seguintes competências para os estados e municípios num regime de cola- boração e sob a assistência da união: Irecensear a população em idade escolar e da educação de jovens e adultos que não tiveram acesso à conclusão da educação básica; II- fazer-lhe chamada pública (BRASIL, 1996, p. 27). De acordo com a resolução no 1 , de 5 de julho de 2000, do Conselho Nacional de educação (CNE) que estabelece As Diretrizes Curriculares Nacionais para a Educação de Jovens e Adultos: A oferta dessa modalidade de ensino deve levar em consideração: os perfis dos estudantes, proporcionando um modelo pedagógico próprio, de modo a assegurar: I. quanto à equidade, a distribuição específica dos componentes curriculares a fim de propiciar um patamar igualitário de formação e restabelecer a igualdade de direitos e de oportunidades face ao direito à educação; II. quanto à diferença, a identificação e o reconhecimento da alteridade própria e inseparável dos jovens e dos adultos em seu processo formativo, da valorização do mérito de cada qual e do desenvolvimento de seus conhecimentos e valores; III. quanto à proporcionalidade, a disposição e alocação adequadas dos componentes curriculares face às necessidades próprias da Educação de Jovens e Adultos com espaços e tempos nos quais as práticas pedagógicas assegurem aos seus estudantes identidade formativa comum aos demais participantes da escolarização básica. (BRASIL, 2000)

Os alunos da EJA são formados por adultos na faixa etária dos 18 aos 80 anos que em algum momento de suas vidas se viram obrigados a abandonar os estudos e agora resolveram voltar, seja por necessidades de trabalho, motivação familiar ou simplesmente para ocupar o tempo. É uma decisão que irá afetar seu modo de vida, envolvendo família, emprego, acessibilidade até a escola, sua autoestima. Para um aluno da EJA,estudar é uma nova chance de retomar sua vida. Ao chegarem à escola trazem consigo resquícios de di- 
versos problemas emocionais, que dificultam o aprendizado (FARIAS, 2010).

São alunos que, em sua maioria, já se encontram inseridos no mercado de trabalho, possuem responsabilidades sociais e familiares, ritmo de aprendizagem e formação de pensamentos muito diferentes e seus valores éticos e morais já formados por experiências tidas anteriormente. Assim, torna-se de extrema importância desenvolver estratégias de ensino que visem despertar o interesse desse seleto grupo (VIANA, 2011). O aluno que trabaIha, muitas vezes chega atrasado, cansado, com sono e com o desejo de não estar na sala de aula (FARIAS, 2010).

A evasão escolar nas classes da EJA é um dos maiores problemas enfrentados por essa modalidade de ensino. Isto ocorre, devido aos mais variados motivos, entre eles: horários incompatíveis com suas responsabilidades, baixa autoestima, falta de professores, por considerarem que a formação recebida não servirá de forma significativa em suas vidas e o desestimulo por parte dos professores e da família (PEDRALLI, 2013).

De acordo com Santos (2014), o aluno da EJA difere-se dos outros por se apresentar um pouco inseguro devido às várias derrotas enfrentadas num processo escolar anterior. Assim, qualquer decepção, fará com que o aluno da EJA deseje abandonar a escola. Muitas escolas e professores acabam por contribuir com a evasão escolar sem nem ao menos se dar conta, com horários e cobranças e com o professor que aborda o conteúdo sem conhecer seus alunos. Santos (2014) propõe que, para resolver o problema de evasão, o professor precisa ajudar seus alunos, buscar compreender e estimular a superação a dificuldade e desafios deles de forma que se sintam acolhidos e isso só é possível através da criação de vínculos afetivos na sala de aula com a finalidade de motivar seus alunos a permanecerem na escola, enfrentando os desafios e cres- cendo como seres humanos. Por meio da afetividade a comunicação é facilitada, professor e aluno se tornam mais próximos e ocorre a redução da evasão escolar. A escola e o professor devem buscar soluções para estimular o aprendizado e devolver a esses alunos a dignidade e o amor próprio muitas vezes em falta nesses alunos (MELLO, 2013).

\section{Objetivo}

O objetivo deste trabalho é discutir de que forma a afetividade, como ferramenta de trabalho docente, em especial com alunos da EJA, pode tornar os estudantes mais receptivos ao aprendizado e ao convívio social. Para alcançar este objetivo, foram realizadas observações e pesquisas, que quando contrastadas com o referencial teórico utilizado, nos disponibilizam uma rica discussão sobre o tema.

\section{MetOdologia}

\section{REFERENCIAL TEÓRICO}

A questão da afetividade tem sido um tema pesquisado e analisado por diversos estudiosos da área da psicologia e da educação. Neste estudo, buscamos entender o papel da afetividade no processo de ensino-aprendizagem com diversos interlocutores, com destaque para: VYGOTSKY (1999), PIAGET (1962), WALLON (1975), FREIRE (1974), ROSSINI (2001), MATURANA (2008), LEITE (2012) E TASSONI (2013), buscando correlacionar seus posicionamentos com a nossa pesquisa.

\section{Cenário e população de estudo}

As observações e levantamentos de dados foram realizados nas aulas de Biologia de uma turma da EJA da rede estadual do Rio de Janeiro, entre os anos de 2015 e 2016. A escola possui 56 alunos e 
12 professores, distribuídos em 3 turmas de Ensino Médio e 4 turmas de EJA. A EJA na rede estadual de educação do estado do Rio de Janeiro visa permitir que jovens e adultos que por algum motivo estavam privados do saber básico concluam em menor tempo essa etapa de ensino, com resultados de aprendizagem e qualidade adequados para a continuidade dos estudos. O Parecer CNE/CEB no 11/2000, que estabelece as diretrizes curriculares nacionais para a EJA, destaca a importância de uma abordagem pedagógica diferenciada. Assim, a EJA deve utilizar metodologia e currículo específicos para jovens e adultos, com material didático próprio. O curso tem duração de dois anos, e é dividido em quatro módulos, um por semestre. Dois módulos têm disciplinas com ênfase em Humanas e os outros dois com ênfase em disciplinas das Ciências da Natureza. Cada módulo tem um número reduzido de disciplinas: mínimo de cinco e máximo de sete. O Ensino Médio na modalidade EJA possui um professor por disciplina, como ocorre no ensino regular. Por dia, o aluno tem três horas e vinte minutos de aulas, que são presenciais, de segunda a sexta-feira (SEEDUC, 2012).

Os alunos participantes da pesquisa possuem faixa etária entre 18 a 65 anos.As observações e obtenção de dados foram autorizadas pela direção da escola e pelos sujeitos de pesquisa através do termo de consentimento livre e esclarecido de acordo com diretrizes e normas regulamentadoras de pesquisas envolvendo seres humanos (BRASIL, 2012).

\section{TIPO DE PESQUisA E INSTRUMENTOS DE COLETA DE DADOS}

Foram realizadas 120 horas de observações nas aulas de Biologia do segundo ano do Ensino Médio. Ainda, foram realizadas entrevistas semiestruturadas, na modalidade entrevista individual com alunos e professores, utilizando questioná- rios. O objetivo da entrevista era verificar a percepção de que aspectos relacionados à afetividade, que os sujeitos da pesquisa conseguiam identificar no processo ensino-aprendizado, principalmente na relação professor-aluno. Foram entrevistados 14 alunos do segundo ano do ensino médio da EJA e 12 professores de diferentes disciplinas, que lecionam para estes alunos. Procurou-se entrevistar os alunos e os professores em um curto espaço de tempo, para evitar a interferência nas respostas. Para a análise dos depoimentos elaboramos uma sequência de sínteses das falas que possibilitaram a sistematização das informações.

\section{ANÁLISE DOS DADOS}

A abordagem qualitativa é considerada como a metodologia mais adequada quando se desejam obter respostas as questões de fundo subjetivas, que não podem ser quantificadas (BARDIN, 2009). Entretanto, a conjugação de elementos qualitativos e quantitativos possibilita ampliar a obtenção de resultados em abordagens investigativas, proporcionando ganhos relevantes para as pesquisas complexas realizadas no campo da Educação. A combinação de dados quantitativos com dados oriundos de metodologias qualitativas pode vir a enriquecer a compreensão. As duas abordagens demandam, no entanto, o esforço da reflexão do pesquisador para dar sentido ao material levantado e analisado (GATTI, 2004).

Para a análise e interpretação dos dados empregamos a técnica da análise de conteúdo proposta por Bardin. Sendo assim, parte do material produzido por meio dos questionários, entrevistas, observações e relatos verbais foram organizados e transcritos visando à definição das unidades de análise. Alguns dados foram ainda utilizados para geração de dados numéricos, conjugando elementos qualitativos e quantitativos, onde foram utilizados 
e-Mosaicos - Revista Multidisciplinar de Ensino, Pesquisa, Extensão e Cultura do Instituto de Aplicação Fernando Rodrigues da Silveira (CAp-UERJ)

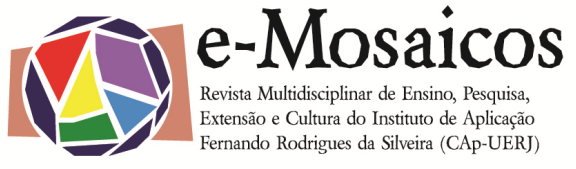

programas específicos de geração de gráficos.

\section{RESULTADOS}

Para uma melhor organização das informações obtidas, procuramos agrupar os dados em: observações, depoimentos e entrevistas. $A$ realização de toda a conduta metodológica nos possibilitou obter dados que possibilitam uma importante discussão sobre a importância da afetividade no trabalho pedagógico com a EJA.

\section{OBSERVAÇõES}

O objetivo das disciplinas do ensino básico é estabelecido, de acordo com os parâmetros curriculares nacionais (PCNs) (BRASIL, 2006). O currículo mínimo do estado do Rio de Janeiro indica os conteúdos que devem ser trabalhados em cada ano de escolaridade. Na EJA, os conteúdos são abordados de forma diferenciada, condensada e de acordo com o material didático elaborado pela SEEDUC (SEEDUC, 2012).

No início do ano letivo as escolas costumam receber material didático impresso que deve ser distribuído para os alunos e aplicado pelos professores, esse material é elaborado para todo o estado do Rio de Janeiro, sem distinção da região. O material da EJA não leva em consideração que é dirigido a um público que está afastado da escola há algum tempo, apresentando os conteúdos de forma confusa e exercícios com um alto grau de dificuldade. Na escola onde efetuamos o presente trabalho a maior parte do material utilizado é elaborado pela professora regente,com uma linguagem de fácil entendimento, com atividades que vão desde pesquisas até exercícios de fixação. $\mathrm{Na}$ escola observada, o objetivo do ensino de Biologia é fazer com que o aluno compreenda fenômenos, aplique conceitos no seu dia a dia e desperte a curiosidade de fazer novas descobertas tudo através de uma linguagem simples. A professora regente utiliza ainda como ferramenta pedagógica a execução de experimentos feitos em sala de aula. Assim, os alunos podem participar de forma ativa e durante as aulas, todos têm o direito de se expressar, perguntar e tirar dúvidas.

Após a análise do manual de orientações da EJA (2015), publicado e distribuído pela SEEDUC, encontramos orientações quanto às atribuições dos professores da EJA. Entre estas atribuições estão: participar das formações pedagógicas e das reuniões de planejamento; organizar e planejar aulas, de acordo com a realidade da turma; estimular a iniciativa, a criatividade e a cooperação dos alunos; introduzir, no cotidiano escolar, assuntos de interesse e significância para os alunos; utilizar técnicas que dinamizem as atividades na turma: trabalhos em grupo, pesquisas, debates, entre outras, de acordo com a nova proposta metodológica; promover de forma instigante a pesquisa e a experimentação; identificar ações que necessitem de correção e de reforço; avaliar sistematicamente os alunos e o trabalho da turma; fornecer ao gestor da unidade escolar e à equipe técnica, as informações necessárias para o bom andamento do trabalho, com fidedignidade e em tempo hábil; realizar autoavaliação permanentemente; e aceitar a mudança e manifestar interesse por novas formas de ensinar e de aprender (SEEDUC, 2015).

Como observado, a afetividade e a relação professor-aluno não é abordada e nem citada entre as atribuições do professor da EJA, deixando margens para inferir que o processo de aprendizagem mecanicista seja aceitável, pois bastaria o professor ter determinadas atitudes procedimentais que o processo de aprendizagem aconteceria por si próprio. A formação continuada do professor é abordada, mas o escopo desta é focado nos conteúdos de aprendizagem, e não em uma obtenção 
e-Mosaicos - Revista Multidisciplinar de Ensino, Pesquisa, Extensão e Cultura do Instituto de Aplicação Fernando Rodrigues da Silveira (CAp-UERJ)

ampla de conhecimentos didáticos. As orientações não enfatizam as relações sociais entre professor e aluno, tratando o ensino de forma mecânica sem respeitar as diferenças existentes entre os indivíduos.

Wallon afirmava que a inteligência é em grande parte fruto do meio social em que está inserido o indivíduo; a escola é um dos principais meio sociais que o individuo frequenta, por isso é importante que seja um ambiente calmo, tranquilo e propicio para trocas de experiências. Durante as aulas observadas todos eram tratados como iguais, as explicações eram dadas como se estivesse em um bate papo com os amigos e todos participavam com comentários e perguntas. Esse ambiente acolhedor fazia com que as aulas fluíssem de forma leve e alegre resultando na meIhoria do aprendizado. O planejamento era realizado com antecedência e com atividades interativas como vídeos, experimentos ou uma conversa sobre algum acontecimento ligado a Biologia. O conteúdo abordado não se prendia unicamente no conteúdo a ser aplicado, caso fosse necessário, a aula era interrompida para ouvir uma sabedoria popular, ou até mesmo escutar um desabafo.

Os alunos eram avaliados por meio de dois instrumentos de avaliação, que consistiam em uma pesquisa e uma prova escrita, além da participação em sala de aula. Diante de todos os aspectos citados, observamos que, o rendimento da turma era muito bom e todos tinham uma grande satisfação em estar em sala.

Ainda, observamos que a afetividade não exerce influência somente nos alunos. O professor ao passar a se sentir querido, exerce sua profissão com muito mais prazer e dedicação, e seus alunos, por sua vez, aprendem com mais satisfação e fazem com que o professor vire um amigo cujas memórias irão acompanhá-los por toda a vida.

\section{Depoimentos}

Durante as observações na EJA foi possível conhecer os alunos e algumas de suas histórias. Entretanto, destacamos dois casos que gostaríamos de relatar, pelos indivíduos em si e também por suas histórias de vida.

$O$ primeiro caso, o aluno $X$, um senhor de 64 anos que trabalha como pedreiro, aprendeu a ler e escrever na EJA e agora cursa o equivalente ao Ensino Médio. O seu maior desejo era concluí-lo e posteriormente tentar uma vaga em um curso de engenharia civil ou arquitetura. $X$ trabalhava muito, pois tinha esposa, dois filhos, uma nora e um netinho, e todos dependiam do seu sustento. O filho mais velho não trabalha. $X$ nos relatou que: "Prefiro que ele estude, pois está cursando Direito e será doutor". X tinha curiosidade em saber como era a faculdade e algumas vezes nos questionava: "Será que eu consigo cursar a faculdade? Será que eu seria aceito pelos colegas de turma?". O ambiente acolhedor criado permitiu que $X$ formasse um grupo de estudos que três vezes por semana se reunia para estudar para o ENEM, contando com o auxílio dos professores. Segundo $X$, a autoestima conquistada e os amigos adquiridos não o deixarão desistir de seus sonhos.

$O$ outro caso é o de $M$, mulher homossexual de aproximadamente 35 anos, sua família não aceitou a sua opção sexual e precisou sair de casa aos 17 anos e por isso deixou a escola. $M$ tinha a autoestima baixa, achava que nunca iria conseguir nada. Um de seus questionamentos foi: "Tenho muito vontade de passar em um concurso público. Será que consigo passar? Tenho medo de não conseguir. "Através do empenho de $M$ e da relação harmoniosa encontrada na escola, hoje $M$ é funcionária pública, recuperou sua autoestima e quer futuramente fazer faculdade. 
Esses são apenas dois de muitos casos encontrados na EJA, todas as turmas são especiais e formadas por seres humanos únicos em formação que devem ser tratados de forma respeitosa e com carinho. A EJA talvez seja mais especial por ser formado por adultos que muitas vezes carregam tristes histórias de vida e experiências escolares fracassadas. É preciso saber trabalhar com eles, entrar em seus mundos, usar sua linguagem e principalmente saber ouvi-los. O professor deve ter em mente que ninguém ficou tanto tempo fora da escola por opção, e que é muito mais difícil voltar a estudar ou começar a fazê-lo depois de adulto.

O sucesso dos alunos pode ser observado também pelo relato da professora de Biologia, que costumava dizer: "se eles saem à noite do trabalho cansados, com fome e com sono para assistir minhas aulas, é meu dever fazer a matéria render o máximo possível, levando para eles um pouco de aprendizado e curiosidade." Assim, suas aulas estavam sempre cheias e repletas de conversas e debates.

\section{ENTREVISTAS}

Para averiguar a percepção dos alunos e professores acerca da relação entre afetividade e aprendizado, foram entrevistados 14 alunos do segundo ano do ensino médio da EJA, e 12 professores, que lecionam para estes alunos. Para os alunos foram feitas quatro perguntas, sendo que três destas tiveram uma resposta "sim" unânime, a saber: a) Você acredita que a afetividade entre professor e aluno ajude no processo de aprendizagem? b) Você se sente mais a vontade em sala de aula para tirar dúvidas quando encontra alguma identificação com o professor? c) Você considera que uma relação de afetividade professor/aluno pode tornar o ensino mais dinâmico e prazeroso?

A quarta pergunta pedia para os alunos selecionarem até três qualidades que eles consideravam importantes em um professor. Todas as seis opções apresentadas foram escolhidas ao menos por um dos entrevistados (figura 1).

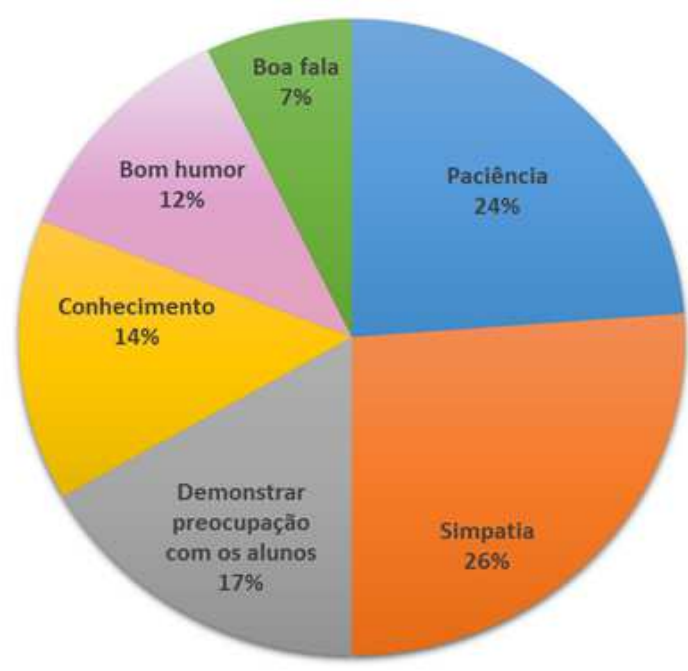

Figura1: Qualidades do professor indicadas pelos alunos do EJA

A análise do gráfico evidencia que os três principais fatores apontados pelos alunos (que somados representam $79 \%$ do total) são justamente os relacionados à afetividade. Os fatores que não estão ligados diretamente à afetividade (boa fala e conhecimento) somam apenas $21 \%$ do total.

Os professores também foram questionados quanto às qualidades do professor, como apresentado na figura 2.

Ao observar as respostas, percebese que os valores estão mais uniformemente preenchidos, a se destacar o pouco valor dado pelo quesito demonstrar preocupação com os alunos, que seria até mesmo merecedor de análise, pois a proposta da EJA é justamente dar um atendimento mais personalizado possível ao aluno, e, sendo assim, a preocupação com o aluno é requisito para alcançar os objetivos intrínsecos à modalidade. 


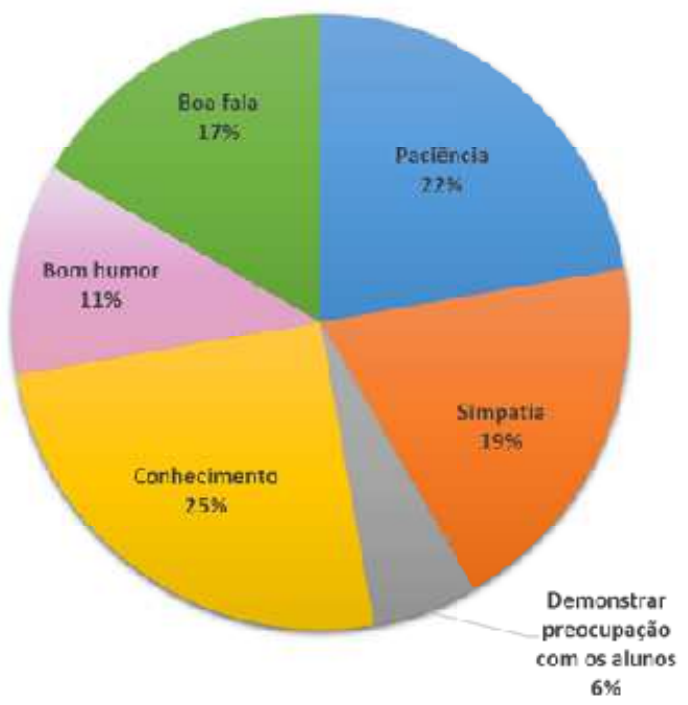

Figura 2: Qualidades do professor indicadas pelos professores do EJA
Nota-se também que entre os professores, as questões mais intimamente relacionadas à afetividade não tem peso consideravelmente maior do que as demais relacionadas; bem diferente das respostas dos alunos.

Para os professores ainda foram feitas sete perguntas. Em relação à resposta dada pelos professores, houve unanimidade em apenas uma das perguntas: Você se considera um professor com um bom relacionamento afetivo com seus alunos? Todos os professores entrevistados responderam sim. Quanto às outras perguntas, os resultados estão apresentados abaixo na tabela 1 :

Tabela 1: Respostas da entrevista realizada com professores do EJA

\begin{tabular}{ccc}
\hline Perguntas & $\begin{array}{c}\text { Respostas } \\
\text { Sim }\end{array}$ & $\begin{array}{c}\text { Respostas } \\
\text { Não }\end{array}$ \\
\hline $\begin{array}{c}\text { Você possui como referência para suas aulas algum } \\
\text { proficssor no qual possuia alguma rclação de } \\
\text { afetividade? }\end{array}$ & 9 & 3 \\
$\begin{array}{c}\text { Você acha que a afetividade entre aluno e professor é } \\
\text { importante? }\end{array}$ & 11 & 1 \\
$\begin{array}{c}\text { Você acredita que existe uma relação entre } \\
\text { afetividade e desenvolvimento cognitivo? }\end{array}$ & 10 & 2 \\
$\begin{array}{c}\text { afetividade se resume apenas em demonstrações de } \\
\text { carinho e contato fisico? }\end{array}$ & 1 & 11 \\
$\begin{array}{c}\text { Para você, a afetividade interfere na disciplina e na } \\
\text { organização da sala de aula? }\end{array}$ & 8 & 4 \\
$\quad$
\end{tabular}

Dessa forma, verifica-se que as concepções de afetividade existem em ambos (corpo docente e discente), há um conhecimento mínimo do tema, porém, há divergências em relação ao impacto da afetividade no processo ensinoaprendizagem, onde os docentes não são unânimes na aceitação deste fato.
É preciso refletir sobre o ato de ensinar, pois além do desenvolvimento de habilidades cognitivas, é necessário despertar o interesse dos alunos, tornando o ambiente mais cativante e estimulante. Os alunos devem ser incentivados a produzirem o próprio pensamento e dessa forma 
e-Mosaicos - Revista Multidisciplinar de Ensino, Pesquisa, Extensão e Cultura do Instituto de Aplicação Fernando Rodrigues da Silveira (CAp-UERJ)

se tornarem aptos a enfrentar questões que surjam ao longo de suas vidas.

\section{DISCUSSÃO}

Vygotsky afirmava que "na ausência do outro, o homem não se constrói" (VYGOTSKY, 1998). Esta afirmativa ficou clara, ao conhecer os alunos que chegavam à escola, inseguros e desconfiados, e ao se sentirem acolhidos começavam a se sociabilizar, ajudando uns aos outros, trocando ideias e experiências. Desta forma enriqueciam não só seu desenvolvimento pedagógico, mas também o seu lado humano era estimulado e cresciam através da afetividade compartilhada. O crescimento não se reservava somente aos alunos, a professora também se beneficiava com essa troca de experiências e vivências. 0 ambiente proporcionado facilitava 0 aprendizado visto que os alunos apresentavam bom desempenho, observado em Biologia. Estes dados estão de acordo com Wallon e Vygotsky que afirmam que a afetividade é essencial para o aprendizado.

Os alunos, por sua vez,na ausência de identificação com o professor e sem nenhum vínculo afetivo que os una, começam a se portar mal dentro da sala de aula, ter baixo rendimento e muitas vezes abandonam os estudos. A escola passa a ser vista como um lugar de obrigações, onde os alunos não têm direitos e apenas deveres. Não há troca de saberes ou ideias, apenas o imposto pelo professor.

A afetividade dentro das salas de aula se mostra de grande importância porque traz o aluno para perto do professor e permite que o conteúdo da disciplina dada seja trabalhado dentro da realidade desses alunos. Dessa forma o saber adquirido pelo aluno será um saber contínuo e não aquele que após a época de provas é esquecido.
Durante nossas observações e pesquisa, percebemos que a afetividade é apontada como um aspecto importante na construção do conhecimento, principalmente pelos alunos. Os professores ainda apresentam algumas dificuldades no entendimento da afetividade como uma estratégia de ensino-aprendizagem. É verdade que as dificuldades encontradas pelos professores são gigantescas, desde a falta de salários dignos e de recursos dentro de sala de aula. Muitos professores esbarram ainda em sua falta de preparo, pois os cursos de licenciatura nem sempre fornecem a base teórica necessária para o preparo do profissional e as escolas não oferecem a seus profissionais cursos de formação continuada. A afetividade muitas vezes é descartada por falta de conhecimento de grandes teóricos como Wallon e Vygotsky, por falta de apoio da equipe pedagógica e ainda por falta de condições do espaço físico onde a escola está inserida.Não adianta o professor ser bem intencionado se não tiver base teórica para agir em sala de aula. A afetividade é uma ferramenta de grande ajuda durante o aprendizado, porém o professor deve estar bem preparado e saber como utilizá-la.

O professor da EJA não deve ser somente aquele que ensina, deve ser 0 que cuida e ensina com afeto, trazendo para a sala de aula um ambiente de aprendizagem ativa e dinâmica, facilitando o convívio do aluno com a turma e com ele próprio e dessa forma ajudando seus alunos a superarem as dificuldades encontradas no ambiente escolar. Ao utilizar a afetividade como ferramenta de trabalho os alunos se sentirão aceitos, possibilitando seu reconhecimento como cidadãos, com direitos e deveres; tornando-os mais receptivos ao aprendizado e melhorando o desempenho escolar. 


\section{CONCLUSÕES}

Nos dias atuais, é indiscutível que a afetividade deve ser considerada no processo de ensino-aprendizagem, mas a sua aplicação é, na maioria das vezes, subestimada na EJA. A afetividade é uma característica intrínseca das relações humanas, que é uma espécie naturalmente social, e por isso mesmo, depende dessas relações para se desenvolver mais efetivamente. $A$ experiência positiva vivida na EJA e descrita neste trabalho permitiu uma comprovação prática da efetividade do fator afetivo para a melhoria do aproveitamento dos alunos, quer seja pela aquisição de conhecimentos, quer seja pelo desenvolvimento humano e construção da individualidade.

Ao confrontar os referenciais teóricos interacionistas com os dados obtidos com a pesquisa, percebe-se que apesar de experiências positivas, ainda são latentes os paradigmas históricos de um ensino tecnicista, mesmo em um projeto que possui - ao menos em teoria - considerações relevantes nos aspectos sociais e humanos do corpo discente. A percepção do papel da afetividade pelos professores é bem menor que nos alunos, e desta forma, não só a EJA é prejudicada em seus preceitos, mas também a própria evasão escolar tem como fator colaborativo a relação distante entre aluno e professor.

Apesar da educação de jovens e adultos ainda ter uma longa estrada para percorrer no Brasil, conclui-se que propostas pedagógicas centradas nos princípios do interacionismo, utilizando a afetividade como ferramenta pedagógica são eficazes, uma vez que formam indivíduos melhor instrumentalizados e conscientes de sua posição na sociedade.

\section{REFERENCIAS BIBLIOGRÁFICAS}

BARDIN, Laurence. Análise de conteúdo. São Paulo: Editora 70, 2009.

BRASIL. Lei 9.394, de 20 de dezembro de 1996. Estabelece as diretrizes e bases da educação nacional. Brasília, 1996.

- Parâmetros curriculares nacionais para o ensino médio. Ministério da Educação. Secretaria de Educação Básica: Brasília, 2006.

. Parecer CNE 11/2000: Diretrizes Curriculares Nacionais para a Educação de Jovens e Adultos. Câmara de Educação Básica: Brasília, 2000.

- Conselho Nacional de Saúde. Resolução $n^{\circ} 466$, de 12 de dezembro de 2012. Aprova normas regulamentadoras de pesquisas envolvendo seres humanos. Diário Oficial da União: Brasília, 2013.

CRUZ, ÉRICA; GONÇALVES, MÁRCIA RIBEIRO; OLIVEIRA, MUNICH RIBEIRO DE. A Educação de Jovens e Adultos no Brasil: Políticas e Práticas. Disponível em <http://www.educacaopublica.rj.gov.br/bi blioteca/educacao/0326.html>. Publicado em 10 de abril de 2012. Acesso em 23 de novembro de 2015.

DI PIERRO, MARIA CLARA; JOIA, ORLANDO; RIBEIRO, VERA MASAGÃO. Visões da educação de jovens e adultos no Brasil. Campinas, Cad. CEDES, v. 21, n. 55, p. 58-77, 2001.

FARIAS, MARIA JAIDETE. O perfil do Aluno da Educação de Jovens e Adultos. Disponível em <http://www.webartigos.com/artigos/operfil-do-aluno-da-educacao-de-jovens-eadultos/34725>. Publicado em 20 de março de 2010. Acesso em 26 de abril de 2016. 
FREIRE, PAULO. Educação e mudança. Coleção Educação e Comunicação vol.1. Rio de Janeiro: Paz e Terra, 1979.

Pedagogia da autonomia: saberes necessários à prática educativa. São Paulo: Paz e Terra, 1996.

- Pedagogia do oprimido. 1.ed. Rio de Janeiro: Paz e Terra 1974.

GALVÃO, ISABEL; Henri Wallon: Uma concepção dialética do desenvolvimento infantil. 4a ed. Editora Vozes, 1995.

GALVÃO, IZABEL. Uma reflexão sobre o pensamento pedagógico de Henri Wallon. Construtivismo em revista. São Paulo, Editora FDE, 1993.

GATTI, BERNADETE. Estudos quantitativos em educação. Educação e Pesquisa. São Paulo, v. 30, n. 1, p. 11-30, jan./abr. 2004.

LA TAILLE, IVES; OLIVEIRA, MARTHA KOHL; DANTAS, HELOYSA. Piaget, Vygotsky, Wallon: teorias psicogenéticas em discussão. São Paulo: Editora Summus, 1992.

LEITE, SERGIO ANTÔNIO DA SILVA. Afetividade nas práticas pedagógicas. Temas em Psicologia - 2012 vol.20, n 2.355- 368. Universidade Estadual de Campinas Campinas, SP, Brasil.

MAHONEY, ABGAIL ALVARENGA; ALMEIDA, LAURINDA RAMALHO. Afetividade e Processo Ensino-Aprendizagem: Contribuições de Henri Wallon. Psicologia da Educação; Versão On-Line ISSN 2175-3520. No.20. São Paulo, 2005.

MATURANA, HUMBERTO. Emoções e linguagem na educação e na política. $1^{a}$ ed. Belo Horizonte: UFMG, 1999.

MATURANA, HUMBERTO; REZEPKA, SIMA NISIS. Formação e humana e capacitação. $5^{\mathrm{a}}$ ed. Rio de Janeiro: Editora Vozes, 2008.

MELLO, TÁGIDES; RUBIO, JULIANA DE ALCÂNTARA SILVEIRA. A Importância da Afetividade na Relação Professor-Aluno no Processo de Ensino-Aprendizagem na Educação Infantil. Revista Eletrônica Saberes da Educação. Faculdade São Roque. Vol.4, no.1, 2013.

PEDRALLI， ROSÂNGELA; CERUTIRIZZATTI, MARY ELIZABETH. Evasão escolar na educação de jovens e adultos: problematizando o fenômeno com enfoque na cultura escrita. Revista Brasileira de Linguística Aplicada, Belo Horizonte, v. 13, n. 3, jul./set. 2013. Disponível em < http://www.scielo.br/pdf/rbla/2013nahead /aop2213.pdf>. Acesso em 10 de outubro de 2016.

PIAGET, JEAN ; INHELDER, BARBEL. A psicologia da criança. São Paulo: DIFEL, 1968.

Psicologia da Inteligência.

Rio de Janeiro: Zahar, 1977.

RODRIGUES, SILVIA ADRIANA; GARMS, GILZA MARIA ZAUHY. Relação ProfessorAluno e Afetividade: Reflexões Wallonianas Sobre o Ambiente de Aprendizagem e a Prática Docente. Série-Estudos - Periódico do Mestrado de Educação da Universidade Católica Dom Bosco. Campo Grande - Mato Grosso do Sul. No. 23, p.31-41. Janeiro - Junho de 2007.

ROSSINI, MARIA AUGUSTA SANCHES. Pedagogia afetiva. Petrópolis: Vozes, 2001.

SANTOS, FÁBIO MAURÍCIO. Afetividade na Prática Docente como Forma de Combater a Evasão Escolar: Experiência com Alunos do Instituto Luciano Barreto Júnior. Caderno Intersaberes. Vol.3, no.4, pg.117 127. Janeiro - Dezembro de 2014. 
SARNOSKI, ELIAMARA APARECIDA. Afetividade no processo ensino aprendizagem. Revista de Educação do Instituto de Desenvolvimento Educacional do Alto Uruguai - IDEAU. Vol.9, no. 20. Dezembro de 2014.

SALLA, FERNANDA. O Conceito de afetividade de Henry Wallon. Disponível em $<$ http://revistaescola.abril.com.br/formaca o/conceito-afetividade-henri-wallon645917.shtml?page $=1>$. Acesso em $12 \mathrm{de}$ março de 2016.

SEBER, MARIA. O diálogo com a criança e o desenvolvimento do raciocínio. São Paulo: Scipione, 1997.

SEEDUC/RIO DE JANEIRO. Secretaria de Educação: Tire suas dúvidas sobre a Nova EJA e o programa autonomia. Disponível em

http://www.rj.gov.br/web/seeduc/exibeco nteudo?article-id $=1264458>$. Publicado em 09 de outubro de 2012. Acesso em 30 de setembro de 2016.

SEEDUC/RIO DE JANEIRO. Manual do Nova EJA. Disponível em $<$ http://projetoseeduc.cecierj.edu.br/eja/ manual-eja.pdf> Acesso em 10 de novembro de 2016.

TASSONI, ELVIRA CRISTINA MARTINS; LEITE, SÉRGIO ANTÔNIO DA SILVA. Afetividade no Processo de EnsinoAprendizagem: As Contribuições da Teoria Walloniana. Educação Vol.36, no.2, pg.262-271. Porto Alegre, 2013.

VIANA, EDITE MARIA SANCHES; RAMPAZZO, JAQUELINE DE SÁ; SILVA, ROSANGELA. A Identidade do Aluno e Professor do EJA. Disponível em $<$ http://www.planetaeducacao.com.br/por tal/artigo.asp?artigo $=2069>$. Acessado em 28 de abril de 2016.
VYGOTSKY, LEV SEMENOVITCH. A formação Social da Mente. São Paulo: Martins Fontes, 1998.

O desenvolvimento psicológico na infância. São Paulo: Martins Fontes, 1999.

. A construção do pensamento e da linguagem. São Paulo: Martins Fontes, 2001.

São Paulo: Artmed, 1999.

WALLON, HENRY. As origens do caráter na criança. São Paulo: Difusão Européia do Livro, 1971.

Do ato ao pensamento: ensaio de psicologia comparada. Petrópolis: Vozes, 2008.

A evolução psicológica da criança. Lisboa, Edições 70, 1941-1995.

Psicologia e educação da infância. Lisboa, Estampa, 1959-1975. 